\title{
Identification of ionizing radiation-responsive microRNAs in the IM9 human B lymphoblastic cell line
}

\author{
HWA JUN CHA ${ }^{1 *}$, SANGSU SHIN $^{1 *}$, HOESOOK YOO ${ }^{1}$, EUN-MEE LEE $^{1}$, SEUNGHEE BAE $^{1}$, \\ KWANG-HEE YANG ${ }^{2}$, SU-JAE LEE ${ }^{3}$, IN-CHUL PARK ${ }^{4}$, YOUNG-WOO JIN ${ }^{2}$ and SUNGKWAN AN ${ }^{1,5}$ \\ ${ }^{1}$ Functional Genoproteome Research Centre, Konkuk University, Seoul 143-701; \\ ${ }^{2}$ Division of Radiation Effect Research, Radiation Health Research Institute of KHNP, Seoul 132-703; \\ ${ }^{3}$ Department of Chemistry, Hanyang University, Seoul 133-791; ${ }^{4}$ Laboratory of Functional Genomics, \\ Korea Institute of Radiological and Medical Sciences, Seoul 139-706; ${ }^{5}$ LIFEnGENE, Inc., Seoul 143-701, Korea
}

Received December 16, 2008; Accepted February 12, 2009

DOI: 10.3892/ijo_00000297

\begin{abstract}
Ionizing radiation (IR) disrupts cellular homeostasis through multiple mechanisms including changes of the expression profile of genes. Although microRNAs (miRNAs), small single-stranded RNAs, have recently been recognized as important post-transcriptional regulators of gene expression, it is not well investigated if miRNAs function in the cellular response to radiation. Therefore, we determined if IR induces changes in the expression profiles of miRNAs and used this approach to identify IR-responsive miRNAs. To monitor the profiles of miRNAs, microarray analysis was conducted with irradiated IM9 human lymphoblastic cells. The expression levels of specific miRNAs were confirmed by quantitative real-time PCR (qRT-PCR) and statistically analyzed. Finally, the target mRNAs of some IR-responsive miRNAs were predicted with two different prediction programs. IR-exposed human lymphoblastic cells underwent cell cycle arrest and apoptosis. Apoptosis was more significantly increased at a higher radiation dose. There were 73 and 33 human miRNAs in 1 and 10 Gy-irradiated cells, respectively that showed expression level changes of $>2$-fold. By qRT-PCR analysis, it was revealed that the patterns of miRNA expression were similar to those observed in the microarray data, although the quantitative expression levels were discordant. Prediction of genes targeted by IR-responsive miRNA yielded several genes, many of which are involved in the regulation of apoptosis, the cell cycle, and DNA repair. The expression profiles of miRNAs in the IM9 human B lymphoblastic cells
\end{abstract}

Correspondence to: Dr Sungkwan An, Functional Genoproteome Research Centre, Konkuk University, 1 Hwayang-dong, Gwangjin-gu, Seoul 143-701, Korea

E-mail: ansfgrc@konkuk.ac.kr

${ }^{*}$ Contributed equally

Key words: microRNA, expression profiles, radiation exposure, IM9, lymphoblast are strongly affected by IR and these changes may be involved in the regulation of cellular response to IR.

\section{Introduction}

Ionizing radiation (IR) is one of the major therapeutic approaches used to treat many types of cancers. The survival or death of irradiated cell depends upon the extent of damage induced by the IR and the level of cytoprotection or unrecoverable cytotoxicity within the cell (1). Induction of reactive oxygen species (ROS) and reactive nitrogen species (RNS) by IR results in damage to DNA, proteins, and lipids, and ultimately changes intracellular signal pathways. Signaling events in response to IR are initiated through DNA damage sensing by ataxia-telangiectasia mutated (ATM), leading to the expression of various cytokines and cytokine receptors such as epidermal growth factor receptor (EGFR) (2) and tumor necrosis factor receptor (TNFR) (3) and the accumulation of ceramides $(4,5)$. In addition, many intermediate signaling molecules including mitogen-activated protein kinases (MAPK), RAS, and TP53 are known to be critical factors in regulating the choice between cell death and cell survival.

Recently, a class of single-stranded RNA molecules of $\sim 22$ nucleotides in length, termed microRNAs (miRNAs), has been shown to function as an important regulator of gene expression (6-9). In most instances, miRNAs are initially transcribed by RNA polymerase II as long primary transcripts (pri-miRNAs) that are processed in the nucleus by the microprocessor complex, consisting of the Drosha and Pasha proteins, into precursor miRNAs (pre-miRNAs) which are generally a $\sim 70$-nucleotide stem-loop structure (10-12). The pre-miRNAs then undergo exportin-5-dependent transport to the cytoplasm (13) followed by further trimming to mature miRNAs by the endonuclease Dicer, a component of the miRNA-induced silencing complex (miRISC) which also includes Argonaute proteins, the double-stranded RNA binding protein TRBP or Argonaute1/2, and the DEAD box helicase RCK/p54 (14-16). However, this maturation process differs for intronic miRNAs (mirtrons), where the Drosha step is bypassed, and in plants, where there is no Drosha homolog $(17,18)$. 
In animal cells, the miRNA within the miRISC binds, usually through imperfect base pairing, to sites within the 3'-UTR of the target mRNA to direct its translational repression. In contrast, in plants, miRNAs generally recognize the coding region of the mRNA with near-perfect complementarity after which they stimulate the cleavage of the target mRNA in a process similar to RNA interference (RNAi) $(6,19-21)$. miRNAs have been implicated in numerous biological processes including developmental timing, cell fate decisions, cell death and proliferation, stem cell function, tumorigenesis and disease (22-26). Recently, other activities of miRNAs have been described, including the activation of gene expression by binding to complementary promoter sequences and the enhancement of translation by interacting with the 5'-UTR of target mRNAs $(27,28)$.

Although there have been many studies on the expression profile and function of genes in the irradiated cell, the expression profile of miRNAs potentially involved in the response to IR has not been thoroughly investigated. In this study, we have used miRNA microarray and quantitative real-time PCR (qRT-PCR) to examine the miRNA expression profile of irradiated IM9 human B lymphoblastic cells. In addition, we have used target prediction methods to determine if differentially expressed miRNAs target IR-related genes. This study provides important findings that will help to understand the miRNA-mediated cellular responses of irradiated cells and its potential importance in therapeutics.

\section{Materials and methods}

Cell culture. The human B lymphoblastic cell line IM9 was cultured in McCoy's 5A medium containing 10\% fetal bovine serum (FBS) and antibiotics at $37^{\circ} \mathrm{C}$ in a humidified chamber supplemented with $5 \% \mathrm{CO}_{2}$. One day before irradiating, $5 \times 10^{5}$ cells were seeded onto 60 -mm culture dishes.

Irradiation and RNA preparation. Cells were cultured for $24 \mathrm{~h}$ prior to irradiation with either 1 or $10 \mathrm{~Gy}$ with a Gammacell ${ }^{\circledR}$ 3000 Elan irradiator ${ }^{137} \mathrm{Cs} \gamma$-ray source; MDS Nordin, ON, Canada). The irradiated cells were maintained for $24 \mathrm{~h}$ before extracting total RNA. The total RNA was extracted with TRIzol ${ }^{\circledR}$ reagent (Invitrogen, CA, USA) according to the manufacturer's protocol. For the microarray studies, the quality and concentration of the RNA samples was determined with an Agilent 2100 Bioanalyzer (Agilent Technologies, CA, USA) and an Ultrospec 3300 Pro UV/Visible Spectrophotometer (Amersham Biosciences, NJ, USA). The recommended RNA quality parameters for the microarray analysis are an OD 260/280 ratio in the range of 1.8-2.0, an OD 260/230 ratio $>1.8$, an $18 \mathrm{~s} / 28 \mathrm{~s}$ rRNA ratio in the range of $1.8-2.1$, and an RNA integrity number (RIN) of $>8.0$.

Analysis of cell cycle and apoptosis by fluorescence-activated cell sorter (FACS). After irradiation, the cells were harvested and counted. For each experiment, $1 \times 10^{6}$ cells were used. For cell cycle analysis, cells were washed twice with $1 \mathrm{ml}$ phosphate-buffered saline (PBS) and resuspended in $100 \mu 1$ PBS. The cells were then fixed for $24 \mathrm{~h}$ at $4^{\circ} \mathrm{C}$ by adding $200 \mu 1$ of $70 \%$ ethanol to the cell suspension. The fixed cells were washed with PBS once and resuspended in $200 \mu 1$ of PBS with RNase (50 $\mu \mathrm{g} / \mathrm{ml}$ final conc.) and incubated at room temperature for $5 \mathrm{~min}$. The cells were then stained with $4 \mu \mathrm{l}$ of $50 \mathrm{mg} / \mathrm{ml}$ propidium iodide (PI; Sigma-Aldrich, MO, USA) at $37^{\circ} \mathrm{C}$ for $5 \mathrm{~min}$. Finally, the cells were analyzed with a BD FACSCalibur (Becton-Dickinson, NJ, USA) flow cytometer. To measure apoptosis, the cells washed twice with PBS and resuspended in $200 \mu 1$ of $1 \mathrm{X}$ Annexin binding buffer. Then, $2 \mu 1$ Annexin V-FITC (BD Biosciences, CA, USA) and $4 \mu 1$ PI $(50 \mu \mathrm{g} / \mathrm{ml})$ were added to the cell suspension and incubated at $37^{\circ} \mathrm{C}$ for $15 \mathrm{~min}$. The stained cells were washed with PBS and analyzed with the FACS system.

Microarray analysis of miRNA profiles. The human miRNA microarray ver. 1 kit (Agilent Technologies), which contains probes for 470 human and 64 viral miRNAs, was adapted to analyze the expression profiles of miRNAs. Before hybridizing the miRNA to the microarray, the total RNA (100 ng) including miRNAs was dephosphorylated with calf intestine alkaline phosphatase (CIP) and denatured by adding DMSO and heating. The dephosphorylated RNA was labeled with pCp-Cy3 by T4 RNA ligase, and the labeled RNA was purified with a Micro Bio-Spin P-6 column (Bio-Rad Laboratories, CA, USA). The purified RNA was denatured and hybridized to the probe on microarray at $55^{\circ} \mathrm{C}$ and $20 \mathrm{rpm}$ in the Agilent Microarray Hybridization Chamber (Agilent Technologies) for $20 \mathrm{~h}$. Then the microarray slide was washed with wash buffers and scanned with the Agilent scanner to obtain the microarray image. The numerical data for the miRNA profiles were extracted from the image with the Feature Extraction program (Agilent Technologies). These data were analyzed with GeneSpring GX software version 7.3 (Agilent Technologies).

qRT-PCR analysis of miRNAs. qRT-PCR was used to confirm the miRNA expression profiles obtained from the microarray data. The template miRNA cDNA was constructed from total RNAs by reverse transcription (RT) with RT-primers from the mirVana qRT-PCR microRNA primer set (Applied Biosystems/Ambion, TX, USA). The PCR was conducted with a Line Gene K real-time PCR machine (Bioer Technology Co., China). The SYBR-Green and U6 gene were used for detecting the gene amplification and normalizing each sample, respectively. The relative quantification of miRNA abundance was calculated with Pfaffl's model after determining the PCR efficiency by the method of Ramussen $(29,30)$.

Target prediction of miRNAs. Candidate miRNAs, which were changed after both radiation doses, were picked for target prediction and analyzed with two target prediction tools, TargetScan 4.2 on the Whitehead Institute for Biomedical Research website (http://www.targetscan.org/) and miRBase Targets Version 5 in the Enright Lab on the Wellcome Trust Sanger Institute website (http://microrna.sanger.ac.uk/ targets/v5/). With TargetScan 4.2, all predicted target genes were selected, whereas only genes showing a best P-value $<0.01$ were selected from by the miRBase Targets Version 5 . Human genes with experimentally verified functions related to apoptosis, cell cycle, or DNA damage and repair were selected from the Gene Ontology website (http://www. geneontology.org/). Finally, the genes predicted to be targets 
A

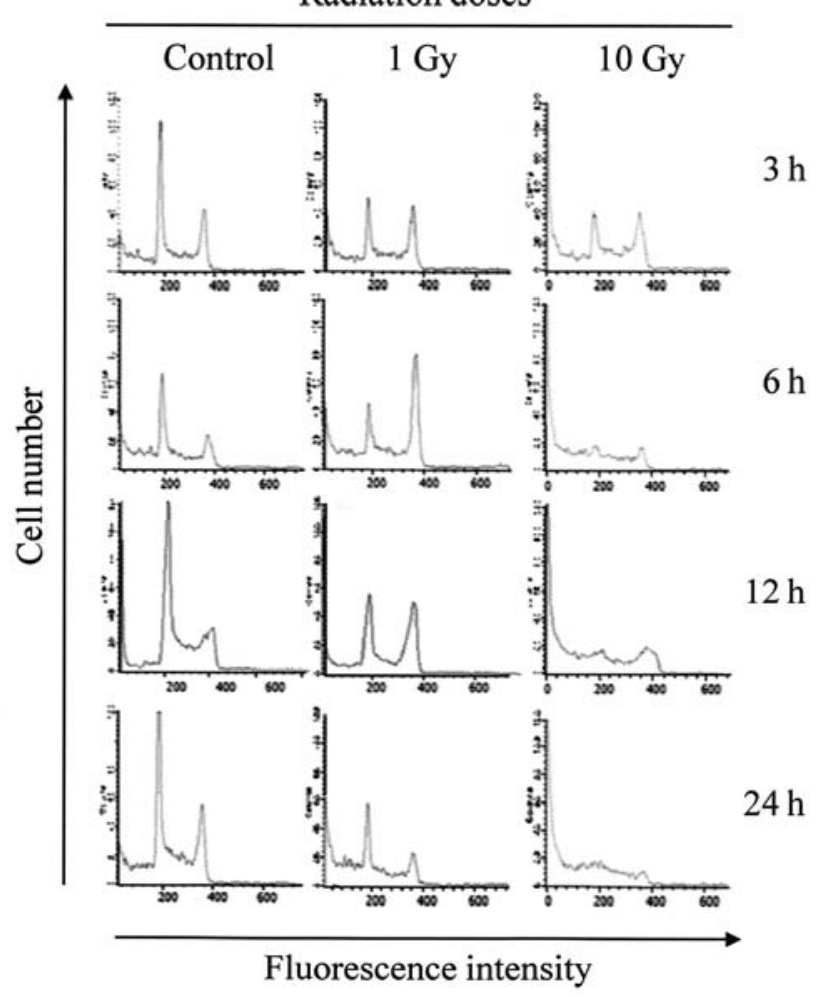

B

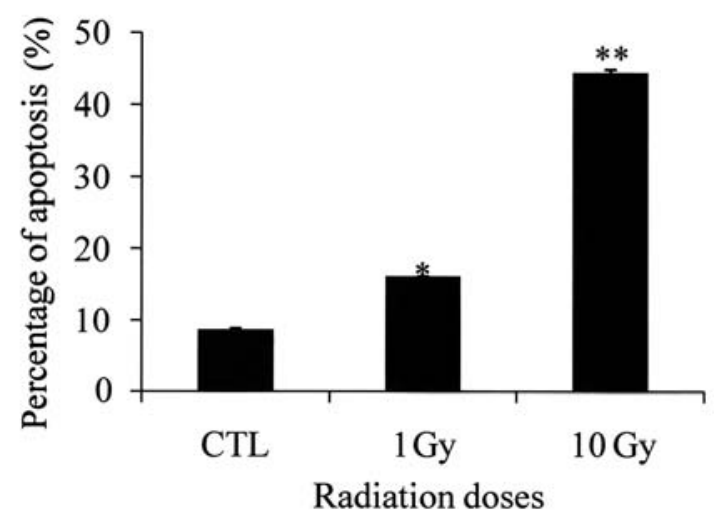

Figure 1. The effect of ionizing radiation on the cell cycle and apoptosis in the IM9 human lymphoblastic cell line. (A) Cell cycle analysis of irradiated human lymphoblastic cells. There are two peaks in the normal cell population, the first represents G0/G1 cells and the other represents G2/M cells. Cells with DNA content less than the G0/G1 cells are apoptotic cells and cells between the two peaks are in S-phase. The normal cell populations were dramatically decreased in the $10 \mathrm{~Gy}$-exposed cells, whereas the fraction of apoptotic cells increased, resulting in a new peak with sub-G0/G1 DNA content. (B) The percentage of apoptotic cells in the total cell pools $24 \mathrm{~h}$ after irradiation. The fraction of apoptotic cells increased to 2- and 5-fold above the control in the 1 and 10 Gy-treated cells, respectively $(\mathrm{P}<0.01)$. of the candidate miRNAs and those selected from the Gene Ontology website were aligned by their gene names and the matched genes were chosen and listed.

Statistical analysis. All numerical data from apoptosis and qRT-PCR assays were analyzed to confirm the effect of radiation doses with one-way analysis of variance (ANOVA). Within each data set, post hoc multiple comparisons were run with Tukey's honestly significant difference (Tukey HSD) to determine the statistical significance for differences between each pair of means. Differences were considered significant at a value of $\mathrm{P}<0.01$.

\section{Results}

IR induces cell cycle arrest or apoptosis in IM9 human B lymphoblastic cells. The major cellular responses to IR, cell cycle arrest and apoptosis, are known to be tightly regulated by ATM (31). To determine how IM9 human B lymphoblasts, which express wild-type p53 (data not shown), respond to irradiation, we treated these cells with 1 or 10 Gy of IR and then monitored cell cycle progression and apoptosis by FACS analysis. The proportion of cells in the G0/G1, S, and G2/M phases of the cell cycle showed marked changes within $3 \mathrm{~h}$ of treatment with both 1 and 10 Gy of radiation (Fig. 1A). In addition, at $24 \mathrm{~h}$ after treatment with either 1 or 10 Gy of IR, we observed significant increases in the fraction of apoptotic cells (Fig. 1B). At this time point, cells treated with 1 Gy showed a 2-fold increase in the fraction of apoptotic cells, and cells treated with 10 Gy showed a 5-fold increase $(\mathrm{P}<0.01)$. This finding was supported by FACS sorting of PI-stained cells, where, following treatment with 10 Gy of IR, the cell population displayed a marked depletion of the G0/G1 and $\mathrm{G} 2 / \mathrm{M}$ phases and a concomitant increase in the sub-G1 fraction (Fig. 1A).

The miRNA expression profile is changed in irradiated cells. The miRNA expression profiles were analyzed with the Agilent human miRNA microarray ver. 1 kit, which can detect 534 mature miRNAs, including 470 human miRNAs and 64 human viral miRNAs. One hundred nanograms of total RNA extracted from IM9 human B lymphoblastic cells exposed to 0,1 , or 10 Gy of IR was labeled and subjected to microarray analysis. The raw data converted from the microarray images with the Agilent Feature Extraction program was normalized by setting all measurements $<0.01$ to a value of 0.01 using Agilent GeneSpring software. A state of each spot that is significant in a microarray analysis is referred to as a flag. The miRNAs were filtered with flags as Present at least 1 of all samples in the normalized data. In total, 134 flagged miRNAs were collected from the 470 testable human miRNAs, and their expression profiles are illustrated in Fig. 2A. Many of these miRNAs showed no changes in expression. However, in the fold-change analysis, 73 and 33 of the flagged miRNAs showed at least a 2-fold change in expression level compared to the control in the $1 \mathrm{~Gy}$ - and 10 Gy-treated samples, respectively. There were 47 miRNAs that showed $<2$-fold change in expression level. The Venn diagram in Fig. 2B represents the number of miRNAs changed only by treatment with 1 Gy of IR, only by treatment with 10 Gy of IR, or by treatment with either dose (the overlap). In total, 19 miRNAs were affected by both doses of IR; however, some of these displayed different expression patterns following each of the two treatments. There were 16 up- 
A

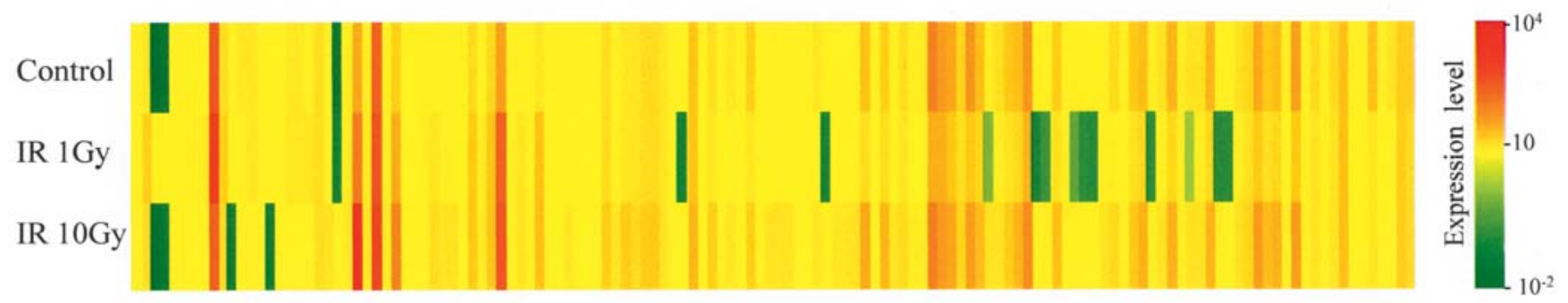

B

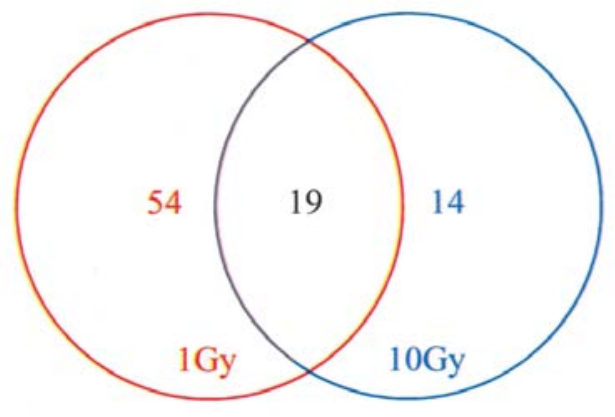

No changes : 47
C

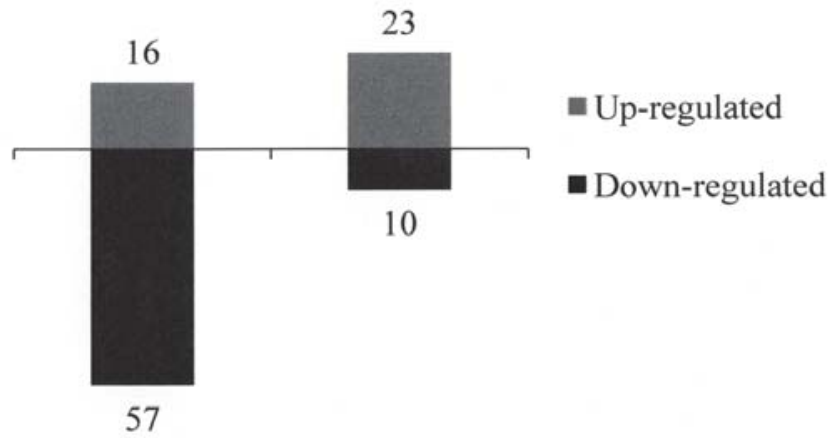

$1 \mathrm{~Gy}$

$10 \mathrm{~Gy}$

Figure 2. Microarray analysis of miRNA expression profiles in response to IR. (A) The expression profiles of human miRNAs. The 134 human miRNAs flagged as Present or Marginal are visualized by color ranging from 0.01 to $10^{4}$. (B) A Venn diagram of miRNAs showing $>2$-fold changes. The flagged miRNAs were analyzed by fold change and sorted by which radiation dose caused the change. In total, 19 miRNAs were altered in both 1 and 10 Gy-irradiated cells. (C) The number of miRNAs up- or down-regulated in each treatment. The miRNAs with expression level changes of $>2$-fold were sorted by expression increase or decrease for each radiation dose.

regulated and 57 down-regulated miRNAs in the cells treated with $1 \mathrm{~Gy}$ of IR, whereas 23 miRNAs were up-regulated and 10 were down-regulated in the 10 Gy-irradiated cells (Fig. 2C). We next filtered this list of IR-responsive miRNAs by statistically assessing the confidence of the measurements and including only those with $\mathrm{P}<0.05$. This filtering step left 36 of 73 miRNAs changed by 1 Gy of IR, and 26 of the 33 miRNAs responsive to 10 Gy of IR (Table I). Of the 62 miRNAs listed in Table I, 13 miRNAs were changed following both radiation doses.

Confirmation of expression profiles of candidate miRNAs by $q R T-P C R$. To confirm the microarray-generated expression profiles of the miRNAs in Table I, we carried out qRT-PCR analysis of the expression level of several of these miRNAs. For each sample, the expression values were normalized to the U6 gene, and we calculated the expression levels relative to the control, untreated cells. Four miRNAs, miR-16, -202, -330 and -572 , were selected for confirmation by qRT-PCR. The microarray data indicated that miR-16 is down-regulated only following $1 \mathrm{~Gy}$, whereas miR-202 and -572 were respectively down- and up-regulated miRNAs by both radiation doses. We selected miR-330, which was down-regulated by 4.4- and 91.4-fold following $1 \mathrm{~Gy}$ and $10 \mathrm{~Gy}$ doses of IR, respectively, as an example to test the validity of the microarray data even though it did not pass the confidence filtering value of $\mathrm{P}<0.05$.
For each candidate miRNA, the qRT-PCR analysis revealed similar patterns of up- and down-regulation to those observed in the microarray analysis (Fig. 3). However, the magnitude of the fold changes in expression differed somewhat between what was observed by microarray analysis and what was observed by qRT-PCR. Nevertheless, it was confirmed that the expression levels of these miRNAs were significantly affected by radiation $(\mathrm{P}<0.01)$.

miRNAs responsive to both radiation doses are predicted to target several genes related to apoptosis, the cell cycle, or DNA damage and repair. Thirteen miRNAs, which were responsive to both radiation doses (see Table I), were subjected to target prediction with TargetScan 4.2 and miRBase Targets Ver. 5. Only genes with $\mathrm{P}<0.01$ were selected from the list of miRBase-predicted targets, whereas all genes predicted to be targets by TargetScan were selected. Genes with functional annotations related to apoptosis (172 genes), cell cycle regulation and arrest (76 genes), or DNA damage and repair (82 genes) were selected from the Gene Ontology website. We then compared the list of target genes predicted by either TargetScan or miRBase Targets to the list of genes selected from Gene Ontology (Table II). Four miRNAs, let-7c, miR-520d, -134, and -630, had no TargetScan-predicted targets found in the three gene ontologies we examined. In contrast, target prediction by miRBase Targets showed that all 
Table I. The list of miRNAs up- or down-regulated by at least 2-fold after radiation exposure. ${ }^{\mathrm{a}}$

\begin{tabular}{|c|c|c|c|c|c|c|c|c|}
\hline \multirow[b]{3}{*}{ Radiation doses } & \multicolumn{8}{|c|}{ miRNA profiles } \\
\hline & \multicolumn{4}{|c|}{ Up-regulated } & \multicolumn{4}{|c|}{ Down-regulated } \\
\hline & Name & $\mathrm{F} / \mathrm{C}^{\mathrm{b}}$ & Name & $\mathrm{F} / \mathrm{C}$ & Name & $\mathrm{F} / \mathrm{C}$ & Name & $\mathrm{F} / \mathrm{C}$ \\
\hline \multirow[t]{12}{*}{$1 \mathrm{~Gy}$} & hsa-miR-560 & 7.8 & hsa-miR-617 & 2.7 & hsa-miR-202 & 5.0 & hsa-miR-18a & 2.7 \\
\hline & hsa-miR-572 & 6.5 & hsa-miR-630 & 2.5 & hsa-miR-142-5p & 4.3 & hsa-let-7c & 2.7 \\
\hline & hsa-miR-557 & 5.6 & hsa-miR-575 & 2.5 & hsa-miR-142-3p & 3.5 & hsa-miR-103 & 2.5 \\
\hline & hsa-miR-663 & 4.6 & hsa-miR-134 & 2.3 & hsa-miR-16 & 3.2 & hsa-let-7a & 2.5 \\
\hline & hsa-miR-638 & 4.2 & hsa-miR-671 & 2.3 & hsa-miR-20a & 3.2 & hsa-miR-21 & 2.4 \\
\hline & hsa-miR-520b & 3.3 & hsa-miR-564 & 2.0 & hsa-miR-106a & 2.9 & hsa-miR-155 & 2.4 \\
\hline & hsa-miR-583 & 3.0 & & & hsa-miR-19b & 2.9 & hsa-miR-93 & 2.2 \\
\hline & & & & & hsa-miR-107 & 2.8 & hsa-miR-29a & 2.2 \\
\hline & & & & & hsa-miR-17-5p & 2.8 & hsa-let-7f & 2.2 \\
\hline & & & & & hsa-miR-15b & 2.8 & hsa-miR-520d & 2.1 \\
\hline & & & & & hsa-miR-146a & 2.7 & hsa-miR-24 & 2.1 \\
\hline & & & & & hsa-miR-106b & 2.7 & & \\
\hline \multirow[t]{10}{*}{$10 \mathrm{~Gy}$} & hsa-miR-630 & 17.1 & hsa-miR-193b & 3.8 & hsa-miR-202 & 5.7 & hsa-miR-197 & 2.6 \\
\hline & hsa-miR-583 & 15.7 & hsa-miR-34a & 3.3 & hsa-miR-520d & 5.7 & hsa-miR-432 & 2.4 \\
\hline & hsa-miR-560 & 13.6 & hsa-miR-365 & 3.3 & hsa-let-7c & 2.7 & hsa-let-7e & 2.0 \\
\hline & hsa-miR-557 & 8.8 & hsa-miR-134 & 3.3 & & & & \\
\hline & hsa-miR-539 & 8.5 & hsa-miR-34b & 2.5 & & & & \\
\hline & hsa-miR-572 & 7.0 & hsa-miR-342 & 2.4 & & & & \\
\hline & hsa-miR-520b & 6.1 & hsa-miR-29c & 2.3 & & & & \\
\hline & hsa-miR-575 & 5.9 & hsa-miR-654 & 2.3 & & & & \\
\hline & hsa-miR-638 & 5.0 & hsa-miR-339 & 2.2 & & & & \\
\hline & hsa-miR-663 & 4.4 & hsa-miR-595 & 2.2 & & & & \\
\hline
\end{tabular}

aThe list was filtered to show only those miRNAs showing at least a 2-fold expression change, with confidence of measurement (t-test P-value) $<0.05$. ${ }^{\mathrm{b}} \mathrm{F} / \mathrm{C}$ means fold-change.

miR-16

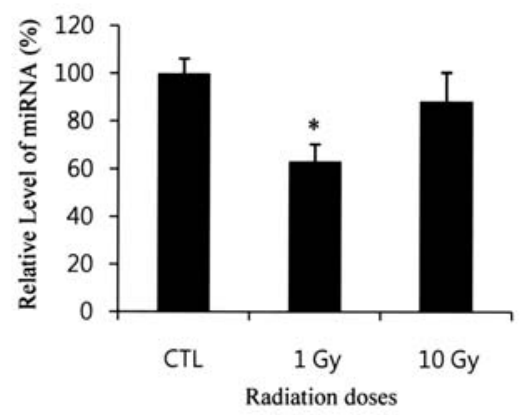

miR-330

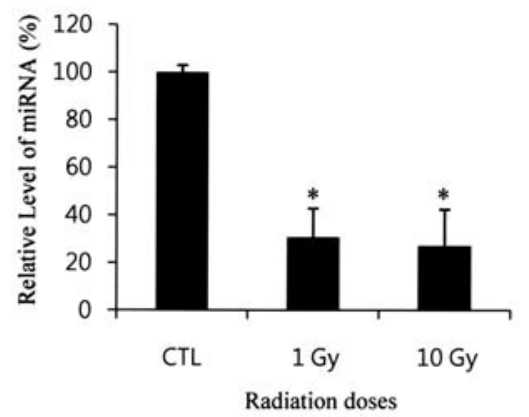

miR-202

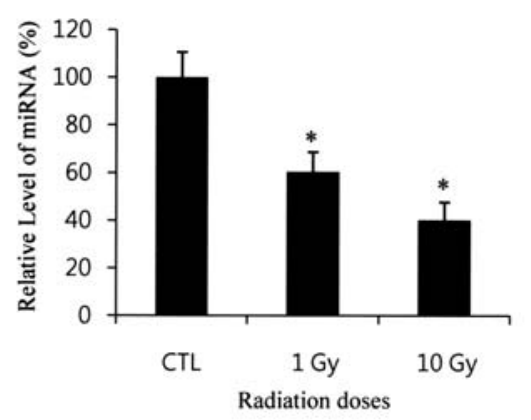

miR-572

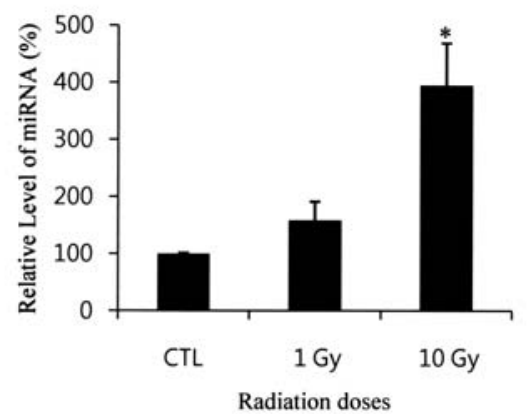

Figure 3. Confirmation of microarray data by qRT-PCR for candidate IR-responsive miRNAs. The expression patterns of four miRNAs, miR-16, -202, -330, and -572 were verified by qRT-PCR. Some of their expression levels were changed significantly by irradiation $(\mathrm{P}<0.01)$. 
Table II. The miRNAs predicted to target genes related to apoptosis, cell cycle, or DNA damage and repair.

\begin{tabular}{|c|c|c|c|c|c|c|c|}
\hline \multirow[b]{2}{*}{$\begin{array}{l}\text { Expression } \\
\text { regulation }\end{array}$} & \multirow[b]{2}{*}{ microRNA } & \multicolumn{3}{|c|}{ TargetScan 4.2} & \multicolumn{3}{|c|}{ miRBase Targets Ver. 5} \\
\hline & & Apoptosis & $\begin{array}{l}\text { Cell } \\
\text { cycle }\end{array}$ & $\begin{array}{l}\text { DNA damage } \\
\text { and repair }\end{array}$ & Apoptosis & $\begin{array}{c}\text { Cell } \\
\text { cycle }\end{array}$ & $\begin{array}{c}\text { DNA damage } \\
\text { and repair }\end{array}$ \\
\hline \multirow[t]{3}{*}{ Down-regulated } & hsa-let-7c & - & - & - & $\begin{array}{l}\text { APOE, AVEN, } \\
\text { BAX, CRTAM, } \\
\text { FASLG, TRADD }\end{array}$ & RCC1, ZW10 & $\begin{array}{l}\text { RPA2, } \\
\text { SMUG1 }\end{array}$ \\
\hline & hsa-miR-202 & $\begin{array}{l}\text { ACVR1C, } \\
\text { DLC1, } \\
\text { FASLG, } \\
\text { GRIK2, IL6 }\end{array}$ & $\begin{array}{l}\text { CCND1, } \\
\text { CCND2, } \\
\text { RBM38 }\end{array}$ & RBM38 & $\begin{array}{l}\text { CIDEB, DYNLL1, } \\
\text { HTATIP2, IFNB1, } \\
\text { LCK, SRGN }\end{array}$ & WDR6 & SMUG1 \\
\hline & hsa-miR-520d & - & - & - & $\begin{array}{l}\text { BAD, BCL6, } \\
\text { BNIPL, BRE, } \\
\text { CASP10, CDKN2A, } \\
\text { ERCC3, FASLG, } \\
\text { HBXIP, P2RX4, } \\
\text { TNFRSF10B }\end{array}$ & $\begin{array}{l}\text { CDC23, } \\
\text { CDKN2A, } \\
\text { DBC1, } \\
\text { GTPBP4, } \\
\text { IL8 }\end{array}$ & $\begin{array}{l}\text { ERCC3, } \\
\text { ERCC5, } \\
\text { EXO1, } \\
\text { POLD1, } \\
\text { POLD2 }\end{array}$ \\
\hline \multirow[t]{10}{*}{ Up-regulated } & hsa-miR-134 & - & - & - & $\begin{array}{l}\text { ANGPTL4, BID, } \\
\text { CDKN2A, CECR2 } \\
\text { GRIK, GSK3B }\end{array}$ & CDKN2A & RFC5 \\
\hline & has-miR-520b & CADM1 & LATS2 & - & $\begin{array}{l}\text { AKT1, BAD } \\
\text { BCL6, BNIPL } \\
\text { BRE, FASLG } \\
\text { P2RX4, } \\
\text { PROK2 }\end{array}$ & GTBP4, IL8 & $\begin{array}{l}\text { ERCC5 } \\
\text { EXO1 } \\
\text { POLD1 } \\
\text { POLD2 }\end{array}$ \\
\hline & hsa-miR-557 & - & $\begin{array}{l}\text { APC, } \\
\text { SMC1A }\end{array}$ & $\begin{array}{l}\text { SMC1A, } \\
\text { VCP }\end{array}$ & $\begin{array}{l}\text { ALB, BCL6, } \\
\text { GRIK2, HTATIP2, } \\
\text { LGALS12, NLRP3 }\end{array}$ & $\begin{array}{l}\text { BMP4, } \\
\text { HEXIM2, }\end{array}$ & $\begin{array}{l}\text { APTX, } \\
\text { NEIL1 }\end{array}$ \\
\hline & hsa-miR-560 & PEA15 & - & - & $\begin{array}{l}\text { CDKN2A, LCK, } \\
\text { MAEA, MIF, } \\
\text { PCBP4, SFN }\end{array}$ & $\begin{array}{l}\text { CDKN2A, } \\
\text { PCBP4, } \\
\text { STK11 }\end{array}$ & $\begin{array}{l}\text { PCBP4, } \\
\text { SFN }\end{array}$ \\
\hline & hsa-miR-572 & SAP30BP & - & - & $\begin{array}{l}\text { ACIN1, CD27, } \\
\text { SFN }\end{array}$ & STK11 & SFN, UPF1 \\
\hline & hsa-miR-575 & $\begin{array}{l}\text { GCLC, } \\
\text { STK4 }\end{array}$ & - & - & $\begin{array}{l}\text { CADM1, } \\
\text { CRYAA, DLC1, } \\
\text { GCLC }\end{array}$ & - & $\begin{array}{l}\text { ERCC4, } \\
\text { GTF2H, } \\
\text { POLD4, } \\
\text { POLG, } \\
\text { POLL }\end{array}$ \\
\hline & hsa-miR-583 & $\begin{array}{l}\text { CADM1, } \\
\text { KIAA1967, } \\
\text { STK4 }\end{array}$ & $\begin{array}{l}\text { APC, } \\
\text { SMC1A }\end{array}$ & SMC1A & PIM1, SIVA1 & $\begin{array}{l}\text { DBC1, } \\
\text { RCC1 }\end{array}$ & DDB1 \\
\hline & hsa-miR-630 & - & - & - & - & GMNN & EXO1 \\
\hline & hsa-miR-638 & - & EDN3 & - & $\begin{array}{l}\text { CIDEB, } \\
\text { DYNLL1, } \\
\text { NLRP3 }\end{array}$ & - & - \\
\hline & hsa-miR-663 & TFGB1 & TGFB1 & - & $\begin{array}{l}\text { ANGPTL4, } \\
\text { APOE, } \\
\text { CRYAA, SFN }\end{array}$ & $\begin{array}{l}\text { BRSK1, } \\
\text { STK11 }\end{array}$ & $\begin{array}{l}\text { BRSK1, } \\
\text { ERCC2, } \\
\text { SFN }\end{array}$ \\
\hline
\end{tabular}

of these miRNAs have potential targets related to at least one of the three gene ontologies. TargetScan predicted 19 target genes for nine of the candidate miRNAs, 11 of which are annotated to be associated with apoptosis. In contrast, miRBase Targets predicted 73 genes targeted by the 13 candidate
miRNAs, of which 42 genes have annotated roles in apoptosis. Among the targets predicted by TargetScan and miRBase targets, only five genes, deleted in liver cancer 1 (DLC1), Fas ligand (FASLG), glutamate receptor, ionotropic kainite 2 (GRIK2), cell adhesion molecule 1 (CADM1), and glutamate- 
cysteine ligase catalytic subunit (GCLC), were predicted to be targets by both algorithms. Interestingly, four of these five genes were predicted to be targeted by different miRNAs by each algorithm, and only one gene, GCLC, was predicted to be targeted by the same miRNA, miR-575.

\section{Discussion}

When cellular damage induced by irradiation exceeds the cell's capacity for repair, specific signaling pathways are activated, leading to changes in gene expression and, ultimately, cell cycle arrest or apoptosis. The gene expression changes associated with the IR response in human lymphoblastoid cells have been well characterized by Akerman et al (32). It was observed that genes related to cell cycle arrest, cellular detoxification, DNA repair, apoptosis, and glutathione metabolism were up-regulated, whereas genes that drive cell proliferation and mitosis were down-regulated in response irradiation. In this study, we confirmed that IM9 human B lymphoblastoid cells respond to 1 and 10 Gy of IR with both cell cycle arrest and apoptosis. Our data indicate that cells arrested in the G2/M cell cycle phases within $6 \mathrm{~h}$ of irradiation and widespread apoptosis was apparent at $24 \mathrm{~h}$ at both doses. However, in cells treated with 10 Gy of IR, apoptosis was apparent in the majority of cells within $6 \mathrm{~h}$ of irradiation.

To gain further insight into the radiation response of human lymphoblastic cells, we monitored the miRNA expression profile in these cells following one of two radiation doses. We observed significant miRNA expression profile changes by microarray analysis in response to IR treatment, and these changes were confirmed for some miRNAs by qRT-PCR. This suggests that miRNAs play a crucial role in cellular and molecular responses to radiation. Our target prediction data suggest that miRNAs responsive to IR may regulate the expression of genes involved in mediating the decision between cell survival and cell death. Among the 134 flagged miRNAs examined in this study, $87(\sim 65 \%)$ showed expression level changes of $>2$-fold. Of these 87 miRNAs, 49 showed statistically significant $(\mathrm{P}<0.05)$ expression level changes in the IR-treated cells. The failure of the remaining miRNAs to reach statistical significance in their fold changes may be due to very low expression levels. Interestingly, we noted different miRNA expression profiles in response to the different doses of IR. Because the cells responded differently to each of these doses, which are primarily by cell cycle arrest in response to $1 \mathrm{~Gy}$ and by apoptosis in response to $10 \mathrm{~Gy}$, we hypothesize that the different miRNA expression profiles reflect different functional outputs that help contribute to the major cellular response to each dose.

Although novel activities of miRNAs have recently been reported, the best understood mechanism of miRNA action is through binding to the 3'UTR of target mRNAs to repress their translation $(19,33)$. We predicted that mRNAs targeted by IR-responsive miRNAs would code for proteins related to apoptosis, cell cycle, and DNA damage and repair. To test this prediction, we used two target prediction algorithms, Target Scan and miRBase Targets, to identify potential targets of the IR-responsive miRNAs. Although there were many apoptosisassociated genes $(\sim 58 \%)$ among the predicted target genes, the outputs of the two algorithms were highly divergent as shown in Table II $(34,35)$. Therefore, the target mRNAs of the IR-responsive miRNAs will have to be verified experimentally. As reported by John et al (36), the target predictions suggested that each miRNA may regulate several mRNAs and a given mRNA could be regulated by multiple miRNAs. Among the predicted targets, GCLC, which was predicted as a target of miR-575 by both programs, has been reported to suppress tumor necrosis factor (TNF)-induced apoptosis and the activation of genes such as nuclear factor- $\mathrm{B}(\mathrm{NF}-\kappa \mathrm{B})$ and activator protein-1 (AP-1) (37). In addition, we noted that miR-34a, a downstream target of p53 that regulates apoptosis and cell cycle arrest (38-40), was up-regulated in $10 \mathrm{~Gy}$ irradiated cells (Fig. 2 and Table I), implying that, in IM9 human B cells expressing wild-type p53 (data not shown), miR-34a may also be involved in the apoptosis and cell cycle response in associated with p53 activation after IR exposure.

In conclusion, the miRNA expression profile of human lymphoblasts is strongly responsive to radiation. These changing miRNAs likely regulate gene expression to influence the cellular response to radiation. This study will be helpful in understanding the cellular mechanisms mediating the response to radiation and will provide some insight into the therapeutic application of radiation.

\section{Acknowledgements}

We are grateful to all other members in our research group for their support and advice in regards to this study. The study reported here was supported by the Ministry of Education, Science and Technology (2007-03151) and the Ministry of Knowledge Economy (R-2006-1-043) of the Republic of Korea.

\section{References}

1. Schmidt-Ullrich RK, Dent P, Grant S, Mikkelsen RB and Valerie K: Signal transduction and cellular radiation responses. Radiat Res 153: 245-257, 2000.

2. Schmidt-Ullrich RK, Valerie K, Fogleman PB and Walters J: Radiation-induced autophosphorylation of epidermal growth factor receptor in human malignant mammary and squamous epithelial cells. Radiat Res 145: 81-85, 1996.

3. Rosette $\mathrm{C}$ and Karin M: Ultraviolet light and osmotic stress: activation of the JNK cascade through multiple growth factor and cytokine receptors. Science 274: 1194-1197, 1996.

4. Haimovitz-Friedman A, Kan CC, Ehleiter D, et al: Ionizing radiation acts on cellular membranes to generate ceramide and initiate apoptosis. J Exp Med 180: 525-535, 1994.

5. Dbaibo GS, Pushkareva MY, Rachid RA, et al: p53-dependent ceramide response to genotoxic stress. J Clin Invest 102: 329-339, 1998.

6. Lee RC, Feinbaum RL and Ambros V: The C. elegans heterochronic gene lin-4 encodes small RNAs with antisense complementarity to lin-14. Cell 75: 843-854, 1993.

7. Lagos-Quintana M, Rauhut R, Lendeckel W and Tuschl T: Identification of novel genes coding for small expressed RNAs. Science 294: 853-858, 2001

8. Lau NC, Lim LP, Weinstein EG and Bartel DP: An abundant class of tiny RNAs with probable regulatory roles in Caenorhabditis elegans. Science 294: 858-862, 2001.

9. Lee RC and Ambros V: An extensive class of small RNAs in Caenorhabditis elegans. Science 294: 862-864, 2001.

10. Lee Y, Kim M, Han J, et al: MicroRNA genes are transcribed by RNA polymerase II. EMBO J 23: 4051-4060, 2004.

11. Lee Y, Jeon K, Lee JT, Kim S and Kim VN: MicroRNA maturation: stepwise processing and subcellular localization. EMBO J 21: 4663-4670, 2002. 
12. Denli AM, Tops BB, Plasterk RH, Ketting RF and Hannon GJ: Processing of primary microRNAs by the Microprocessor complex. Nature 432: 231-235, 2004.

13. Yi R, Qin Y, Macara IG and Cullen BR: Exportin-5 mediates the nuclear export of pre-microRNAs and short hairpin RNAs. Genes Dev 17: 3011-3016, 2003.

14. Bernstein E, Caudy AA, Hammond SM and Hannon GJ: Role for a bidentate ribonuclease in the initiation step of RNA interference. Nature 409: 363-366, 2001.

15. Gregory RI, Chendrimada TP, Cooch N and Shiekhattar R: Human RISC couples microRNA biogenesis and posttranscriptional gene silencing. Cell 123: 631-640, 2005.

16. Chu CY and Rana TM: Potent RNAi by short RNA triggers. RNA 14: 1714-1719, 2008

17. Kurihara Y and Watanabe Y: Arabidopsis micro-RNA biogenesis through Dicer-like 1 protein functions. Proc Natl Acad Sci USA 101: 12753-12758, 2004.

18. Ruby JG, Jan $\mathrm{CH}$ and Bartel DP: Intronic microRNA precursors that bypass Drosha processing. Nature 448: 83-86, 2007.

19. Lai EC: MicroRNAs are complementary to 3'-UTR motifs that mediate negative post-transcriptional regulation. Nat Genet 3: 363-364, 2002

20. Llave C, Xie Z, Kasschau KD and Carrington JC: Cleavage of scarecrow-like mRNAtargets directed by a class of Arabidopsis miRNA. Science 297: 2053-2056, 2002

21. Tang G, Reinhart BJ, Bartel DP and Zamore PD: A biochemical framework for RNA silencing in plants. Genes Dev 17: 49-63, 2003

22. Ambros V: The functions of animal microRNAs. Nature 431: 350-355, 2004

23. Alvarez-Garcia I and Miska EA: MicroRNA functions in animal development and human disease. Development 132: 4653-4662, 2005 .

24. Kent OA and Mendell JT: A small piece in the cancer puzzle: microRNAs as tumor suppressors and oncogenes. Oncogene 2: 6188-6196, 2006.

25. Lin SL, Chang DC, Chang-Lin S, et al: Mir-302 reprograms human skin cancer cells into a pluripotent ES-cell-like state. RNA 14: 2115-2124, 2008

26. Marson A, Levine SS, Cole MF, et al: Connecting microRNA genes to the core transcriptional regulatory circuitry of embryonic stem cells. Cell 134: 521-533, 2008.

27. Place RF, Li LC, Pookot D, Noonan EJ and Dahiya R: MicroRNA-373 induces expression of genes with complementary promoter sequences. Proc Natl Acad Sci USA 105: 1608-1613, 2008 .
28. Ørom UA, Nielsen FC and Lund AH: MicroRNA-10a binds the 5'UTR of ribosomal protein mRNAs and enhances their translation. Mol Cell 30: 460-471, 2008.

29. Pfaffle MW: A new mathematical model for relative quantification in real-time RT-PCR. Nucleic Acids Res 29: e45, 2001.

30. Rasmussen R: Quantification on the light cycler. In: Rapid Cycle Real Time PCR: Methods and Applications. Meuer S, Wittwer C and Nakagawara K (eds). Springer Press, Heidelberg, pp21-34, 2001.

31. Barlow C, Brown KD, Deng CX, Tagle DA and Wynshaw-Boris A: ATM selectively regulates distinct p53-dependent cell-cycle checkpoint and apoptotic pathways. Nat Genet 17: 453-456, 1997.

32. Akerman GS, Rosenzweig BA, Domon OE, et al: Alterations in gene expression profiles and the DNA-damage response in ionizing radiation-exposed TK6 cells. Environ Mol Mutagen 45: 188-205, 2005

33. Baek D, Villén J, Shin C, et al: The impact of microRNAs on protein output. Nature 455: 64-71, 2008

34. Lewis BP, Shih IH, Jones-Rhoades MW, Bartel DP and Burge CB: Prediction of mammalian microRNA targets. Cell 115: 787-798, 2003.

35. Enright AJ, John B, Gaul U, et al: MicroRNA targets in Drosophila. Genome Biol 5: R1, 2003.

36. John B, Enright AJ, Aravin A, et al: Human microRNA targets. PLoS Biol 2: e363, 2004

37. Manna SK, Kuo MT and Aggarwal BB: Overexpression of $\gamma-$ glutamylcysteine synthetase suppresses tumor necrosis factorinduced apoptosis and activation of nuclear transcription factor-kappa B and activator protein-1. Oncogene 18: 4371-4382, 1999.

38. Chang TC, Wentzel EA, Kent OA, et al: Transactivation of miR-34a by p53 broadly influences gene expression and promotes apoptosis. Mol Cell 26: 745-752, 2007.

39. Tarasov V, Jung $\mathrm{P}$, Verdoodt $\mathrm{B}$, et al: Differential regulation of microRNAs by p53 revealed by massively parallel sequencing: miR-34a is a p53 target that induces apoptosis and G1-arrest. Cell Cycle 6: 1586-1593, 2007.

40. Sun F, Fu H, Liu Q, et al: Downregulation of CCND1 and CDK6 by miR-34a induces cell cycle arrest. FEBS Lett 582: 1564-1568, 2008. 